\title{
Mengkonstruk Masa Depan Nahdlatul Ulama (Studi tentang Rekomendasi Kebijakan Konfercab XVII PCNU Kabupaten Blitar)
}

\author{
Arif Muzayin Shofwan ${ }^{1}$ \\ ${ }^{1}$ Universitas Nahdlatul Ulama Blitar \\ Email: ${ }^{1}$ arifms78@yahoo.co.id
}

\begin{tabular}{l} 
Tersedia Online di \\
\hline http://www.jurnal.unublitar.ac.id/ \\
index.php/briliant \\
\hline \\
\hline Sejarah Artikel \\
Diterima pada 2 Januari 2018 \\
Disetuji pada 2 Januari 2018 \\
Dipublikasikan pada 13 Februari \\
2018 Hal. 1-12
\end{tabular}

Kata Kunci:

konstruksi Sosial, kebijakan,

nahdlatul ulama

\section{DOI:}

http://dx.doi.org/10.28926/briliant .v3i1.126

\begin{abstract}
Abstrak: Nahdlatul Ulama (NU) merupakan organisasi keagamaan Islam terbesar di Indonesia yang didirikan oleh ulama pondok pesantren di Surabaya pada tanggal 31 Januari 1926. Ormas ini mulai masuk dan berdiri sebagai cabang di kabupaten Blitar sejak tahun 1352 H/ 1951 M yang pertama kali diketuai oleh Kiai Haji Zahid Syafii. Hingga kini, NU cabang Blitar ini telah melakukan Konfercab ke-XVII. Tulisan kualitiatif dengan pendekatan teori konstruksi sosial ini merupakan studi tentang rekomendasi kebijakan Konfercab XVII NU di kabupaten Blitar untuk masa khidmat 2017-2022. Berdasarkan hal tersebut, tulisan ini menghasilkan bahwa para ulama dan pengurus NU cabang Blitar dalam konfercab XVII NU tersebut telah mengkonstruk beberapa rekomendasi kebijakan yang ditujukan kepada Pemerintah Kabupaten Blitar meliputi lima hal, yaitu bidang pendidikan, ekonomi, sosial, kesehatan, dan partisipasi masyarakat. Selain itu, konfercab ini juga mengkonstruk beberapa kebijakan yang ditujukan kepada pengurus cabang NU kabupaten Blitar terbaru dan warga NU secara keseluruhan dalam rangka membangun sinergi menuju NU ke depan yang lebih mandiri..
\end{abstract}

Hingga kini penelitian tentang Nahdlatul Ulama (NU) telah banyak dilakukan oleh para peneliti baik dari dalam negeri maupun luar negeri. Namun penelitian tersebut menurut Hakam (2017) kebanyakan terkait dengan historiografi NU yang selama ini berkutat pada tokoh-tokoh besar dalam pentas nasional di Jakarta. Masih menurut Hakam bahwa kajian tentang NU tersebut lebih cenderung pada tema-tema politik. Dengan demikian, tampaknya masih jarang penelitian NU yang berfokus pada cabang yang berada di berbagai kabupaten, bahkan ranting yang berada diberbagai kecamatan. Lebih-lebih apabila penelitian tersebut dikaitkan dengan konstruksi sosial para ulama dan pengurus NU cabang terutama mengenai arah kebijakan NU untuk masa mendatang.

Sebenarnya segala yang terjadi saat ini merupakan hasil konstruksi sosial di masa lalu, dan apa yang akan terjadi di masa mendatang merupakan hasil konstruksi sosial saat ini. Dengan demikian, bisa dikaji bahwa apa yang terjadi dalam tubuh cabang NU kabupaten Blitar saat ini merupakan hasil dari konstrukti sosial para ulama dan pengurus NU cabang Blitar terutama terkait arah kebijakan konferensi cabang (konfercab) masa lalu, dan apa yang akan terjadi dalam tubuh NU kabupaten Blitar mendatang juga tidak lepas dari konstruksi sosial para ulama 
dan pengurung NU cabang Blitar terkait dengan arah kebijakan yang dilakukan saat ini. Tentu saja, hal itu semua dapat dilihat dengan pisau analisis berupa teori konstruksi sosial Berger dan Lukcmann (2013) yang meliputi tiga momen penting yaitu, eksternalisasi, objektivasi, dan internalisasi.

Pengertian ketiga momen dalam teori konstruksi sosial Berger dan Luckmann tersebut dapat dijelaskan Ngangi (2011) sebagai berikut; Pertama, eksternalisasi adalah usaha pencurahan diri manusia ke dalam dunia, baik dalam kegiatan mental maupun fisik. Sudah merupakan hakikat manusia sendiri, dan merupakan kehendak antropologis, manusia selalu mencurahkan diri ke dalam dunia tempat ia berada. Manusia tidak dapat kita mengerti sebagai ketertutupan yang lepas dari dunia luarnya.

Kedua, objektivasi adalah hasil yang telah dicapai baik mental maupun fisik dari kegiatan eksternalisasi manusia. Hasil itu menghadapi sang penghasilnya sendiri sebagai suatu faksitisas yang ada di luar dan berlainan dari manusia yang menghasilkannya. Lewat proses ini masyarakat menjadi suatu realitas sui generis.

Ketiga, internalisasi yaitu penyerapan kembali dunia objektif ke dalam kesadaran sedemikian sehingga subjektif individu dipengaruhi oleh struktur dunia sosial. Macam-macam unsur dari dunia yang diobjektivasikan akan ditangkap sebagai gejala realitas di luar kesadarannya sekaligus sebagai gejala internal bagi kesadaran. Melalui internalisasi manusia menjadi hasil masyarakat.

Berawal dari itulah, tentu saja konfercab XVII PCNU Kabupaten Blitar dengan tema Membangun Sinergi Menuju NU Mandiri yang dilaksanakan di Pondok Pesantren Mahyajatul Qurra' Kunir, 22-24 Desember 2017 untuk masa mendatang tidak akan bisa lepas dari hasil arah kebijakan yang dikonstruk para ulama dan pengurus NU cabang kabupaten Blitar di masa kini, yang meliputi tiga momen sebagaimana tersebut di atas. Berdasarkan hal inilah maka melakukan studi tentang arah kebijakan yang telah dikonstruk para ulama dan pengurus Nahdlatul Ulama (NU) pada konfercab XVII PCNU Kabupaten Blitar merupakan sesuatu hal yang sangat menarik untuk dilakukan.

\section{METODE}

Tulisan tentang studi kebijakan konfercab XVII PCNU Kabupaten Blitar masa khidmat 2017-2022 ini merupakan penelitian kualitatif yang menggunakan teori konstruksi sosial Berger dan Lukcmann sebagai pisau analisisnya. Selain menggunakan teori konstruksi sosial Berger dan Lukcmann sebagai teori besarnya, tulisan ini juga menggunakan studi kasus sebagai pendekatannya. Merupakan studi kasus dengan alasan karena studi ini dilakukan terhadap suatu kesatuan sistem, yang berupa program, kegiatan, peristiwa, atau sekelompok individu yang terikat oleh tempat, waktu atau ikatan tertentu (Stake, 1994), yakni di Konfercab XVII NU kabupaten Blitar yang diselenggarakan di Pondok Pesantren Mahyajatul Qurro’ Kunir, 22-24 Desember 2017.

Penelitian ini juga merupakan penelitian kualitatif yang menurut Bogdan \& Biklen (1998) sebab memiliki lima karakteristik khusus, yaitu: (a) naturalistic; (b) deskriptif; (c) perhatian pada proses (d) induktif; dan (e) perhatian pada makna. Dengan demikian penilitian ini akan fokus pada proses konfercab XVII NU kabupaten Blitar yang terjadi di Pondok Pesantren Mahyajatul Qurro' Kunir, Wonodadi, Blitar. Karena berfokus pada proses, maka penelitian ini juga bersifat 
alamiah (naturalistic) dan induktif sebagaimana yang dikatakan kedua pakar ahli tersebut.

\section{HASIL}

Studi ini menghasilkan beberapa temuan antara lain bahwa konfercab XVII NU kabupaten Blitar yang dilaksanakan di Pondok Pesantren Mahyajatul Qurro' Kunir, Wonodadi, Blitar pada tanggal 22-24 Desember 2017 memberikan bukti bahwa para ulama dan pengurus NU cabang Blitar telah mengkonstruk beberapa rekomendasi kebijakan yang ditujukan kepada Pemerintah Kabupaten Blitar meliputi lima hal, yaitu bidang pendidikan, ekonomi, sosial, kesehatan, dan partisipasi masyarakat. Selain itu, konfercab ini juga mengkonstruk beberapa tausiyah atau rekomendasi kebijakan yang ditujukan kepada pengurus cabang NU kabupaten Blitar terbaru dan warga NU secara keseluruhan dalam rangka membangun sinergi menuju NU ke depan yang lebih mandiri.

Tentu saja, rekomendasi kebijakan yang dikeluarkan konfercab XVII NU kabupaten Blitar tersebut apabila dianalisis dengan teori konstruksi sosial Berger dan Luckmann merupakan bagian dari eksternalisasi para ulama dan pengurus NU cabang kabupaten Blitar yang di masa mendatang diharapkan akan melembaga atau menjadi pola serta terinternalisasi dalam diri pemangku kebijakan Pemerintahan Kabupaten Blitar, pengurus NU kabupaten Blitar, dan warga Nahdliyin (NU) se-kabupaten Blitar hingga akhirnya benar-benar menjadi sebuah pola pikir, sikap, dan tindakan yang real dan selaras dengan tema konfercab tersebut, yakni membangun sinergi demi terwujudnya NU mandiri.

\section{PEMBAHASAN}

\section{Sekelumit tentang NU di Kabupaten Blitar}

Pada tanggal 31 Januari 1926 terjadi pertemuan para ulama pesantren di kampung Kertopaten Surabaya. Pertemuan para ulama tersebut bermaksud membahas dan menunjuk delegasi komite Hijaz yang hendak dikirim untuk menyampaikan pesan kepada Raja Abdul Aziz Ibnu Saud, penguasa baru Hijaz, Saudi Arabia (Anam, 2010). Pertemuan para ulama pesantren tersebut juga sebagai tanda berdirinya sebuah organisasi kemasyarakatan yang hingga kini disebut Nahdlatul Ulama (NU). Ormas NU memang tidak didirikan oleh satu orang tokoh semata, namun ia didirikan oleh para ulama pondok pesantren yang berkumpul di Kertopaten Surabaya kala itu (Tim Revisi POA PWNU Jawa Timur, 2015).

Siradj (2012) menyebutkan beberapa tokoh ulama angkatan pertama yang menjadi pelopor dalam proses berdirinya Nahdlatul Ulama (NU), antara lain: Kiai Muhammad Hasyim Asyari (Jombang), Kiai Abdul Wahab Hasbullah (Jombang), Kiai As'ad Syamsul Arifin (Situbondo), Kiai Abdul Karim (Lirboyo, Kediri), Kiai Mas Nawawi bin Noerhasan (Sidogiri), Kiai Ridwan Abdullah (Surabaya), Kiai Bisri Syansuri (Jombang), Kiai Ma'shum (Lasem), Kiai Cholil Harun (Rembang), Kiai Muhammad Siddiq (Jember), Kiai Muhammad Hasan (Genggong), Kiai Abdullah Mubarok (Suryalaya, Tasikmalaya), Kiai Munawwir (Yogyakarta), dan lain sebagainya. Tentu saja, masih ada banyak ulama pesantren yang belum disebutkan Siradj sebagaimana tersebut.

Sementara itu, Mujamil Qomar (2002) dalam Imron (2016) menyebut tiga nama ulama yang memiliki peran penting dalam proses pendirian Nahdlatul 
Ulama (NU), yaitu: Kiai Abdul Wahab Hasbullah (Jombang) sebagai pencetus ide; Kiai Muhammad Hasyim Asyari (Jombang) sebagai pemegang kunci; dan Kiai Muhammad Kholil (Bangkalan) sebagai penentu berdirinya Nahdlatul Ulama (NU). Bahkan Imron (2016) menambahkan Kiai As'ad Syamsul Arifin (Situbondo) sebagai penyampai isyarah langit dari Kiai Muhammad Kholil (Bangkalan) yang telah meneguhkan sikap dan pandangan Kiai Muhammad Hasyim Asyari (Jombang) untuk mendirikan Nahdlatul Ulama.

Sebagai ormas yang berfaham Ahlussunnah wal Jamaah (Aswaja), NU dalam hal teologi (akidah/tauhid) mengikuti Imam Asy'ari dan Imam Maturidi. Sedangkan dalam hukum fikih, NU mengikuti empat imam madzhab, yaitu Imam Hanafi, Imam Maliki, Imam Syafii, dan Imam Hambali. Sementara itu, dalam bidang tasawuf (akhlak), NU mengikuti Imam Ghazali dan Imam Junaidi alBaghdadi (Abdusshomad, 2010; Tim Aswaja NU Center PWNU Jawa Timur, 2016). Selain itu, Nahdlatul Ulama mendasarkan paham keagamaannya empat sumber ajaran Islam, yaitu: al-Qur'an, al-Hadist, al-Ijma' (kesepakatan para Sahabat dan ulama), dan al-Qiyas atau analogi (Fadeli dan Subhan, 2012).

Menurut Fadeli dan Subhan (2012) secara garis besar, pendekatan kemasyarakatan NU dapat dikategorikan menjadi tiga bagian. Pertama, tawassuth dan $i$ 'tidal, yaitu sikap moderat yang berpijak pada prinsip keadilan serta berusaha menghindari segala bentuk yang ekstrim (tatharruf). Kedua, tasamuh, yaitu sikap toleran yang berintikan penghargaan terhadap perbedaan pandangan dan kemajemukan identitas budaya masyarakat. Ketiga, tawazun, yaitu sikap seimbang dalam berkhidmat demi terciptanya keserasian hubungan antara sesama umat manusia dan antara manusia dengan Allah Swt.

Secara keseluruhan, NU sebagai ormas keagamaan terbesar di Indonesia, dia memiliki 14 lembaga, 2 lajnah, dan 10 badan otonom (banom). Empat belas lembaga tersebut antara lain: LDNU, LP Maarif, RMI, LPNU, LP2NU, LKKNU, Lakpesdam, LPBH NU, Lesbumi, LAZIZNU, LWPNU, LBM, LTMI, LPKNU. Adapun dua lajnah itu adalah Lajnah Ta'lif Wan Nasyr (LTN) dan Lajnah Falakiyah. Sedangkan sepuluh badan otonom (banom) itu antara lain: Muslimat NU, Fatayat NU, GP Ansor, IPNU, IPPNU, ISNU, Sarbumusi, IPSNU Pagar Nusa, Jam'iyah Ahli Thariqah, dan JQH (Fadeli dan Subhan, 2014).

Lain daripada hal di atas, dalam Anggaran Dasar Nahdlatul Ulama Bab I tentang Nama, Kedudukan, dan Status pada Pasal 2 disebutkan bahwa Nahdlatul Ulama (NU) berkedudukan di Jakarta, Ibukota Negara Republik Indonesia yang merupakan tempat kedudukan Pengurus Besar (PB)-nya. Sedangkan dalam Bab VI tentang Struktur dan Perangkat Organisasi pada Pasal 12 disebutkan bahwa struktur organisasi Nahdlatul Ulama terdiri atas enam kepengurusan, yaitu: (1) Pengurus Besar berkedudukan di Jakarta; (2) Pengurus Wilayah berkedudukan di propinsi; (3) Pengurus Cabang berkedudukan di kabupaten dan Pengurus Cabang Istimewa berkedudukan di luar negeri; (4) Pengurus Wakil Cabang berkedudukan di kecamatan; (5) Pengurus Ranting berkedudukan di desa; dan (6) Pengurus Anak Ranting berkedudukan di dusun. Berdasarkan kepengurusan inilah, seputar tahun 1951, ormas NU mulai beroperasi membuka cabang di kabupaten Blitar.

Ormas Nahdlatul Ulama (NU) tercatat masuk ke kabupaten Blitar tepatnya sejak tahun $1352 \mathrm{H} / 1951 \mathrm{M}$, dan sebagai ketua pertama adalah Kiai Zahid Syafii dari Pondok Pesantren Bustanul Mutaallimin, Dawuhan, kota Blitar, dan sebagai rais adalah Kiai Mochsin yang makamnya berada di barat Masjid 
Agung Kota Blitar. Adapun secara berurutan hingga sekarang, Rais PCNU Kabupaten Blitar dari generasi ke generasi dapat dijelaskan sebagai berikut, antara lain: (1) Kiai Mochsin, tahun 1951/1960; (2) Kiai Zahid Syafii, tahun 1960/1970; (3) Kiai Zahid Syafii, tahun 1971/1978; (4) Kiai Zahid Syafii, tahun 1979/1982; (5) Kiai Zahid Syafii, tahun 1981/1984; (6) Kiai Anwar Sudibjo, tahun 1985/1988; (7) Kiai Anwar Sudibjo, tahun 1987/1988; (8) Kiai Ahmad Zainuddin, tahun 1988/1991; (9) Kiai Ahmad Zainuddin, tahun 1992/1996; (10) Kiai Ahmad Zainuddin, tahun 1997/2002; (11) Kiai Ahmad Zainuddin, tahun 2002/2007; (12) Kiai Shohib Hasan, tahun 2007/2012; (13) Kiai Imam Suhrowardi, tahun 2012/2017; dan (14) Kiai Muhammad Ardani Ahmad, tahun 2017/2022.

Hingga kini, NU cabang Kabupaten Blitar berdasarkan surat keputusan LP. Maarif NU Kabupaten Blitar nomor 238/PC.30/SK/LPMNU/VI/2017 secara keseluruhan (global) tercatat memiliki lembaga pendidikan tingkat MI, MTs, SMP, SD Plus, Madrasah Diniyah (MADIN), Raudlatul Atfal (RA), Taman Kanak-kanak (TK), Taman Pendidikan al-Qur'an (TPQ), dan Pondok Pesantren sebanyak 567 buah. Data tersebut merupakan data keseluruhan yang terlampir dalam surat keputusan LP. Maarif NU tersebut.

Selain itu, Tim Penyusun (2017) menyebutkan bahwa NU Kabupaten Blitar hingga kini juga aktif mengurusi beberapa lembaga berikut antara lain: Rabithah Al-Ma'ahid Al-Islamiyah (RMI) NU Kabupaten Blitar yang pada periode 2013/2017 diketuai oleh Kiai Ahmad Mudlofi; Lembaga Kemaslahatan Keluarga Nahdlatul Ulama (LKKNU) yang pada saat periode 2013/2017 diketuai oleh Haji Hafidz Lutfi; Lembaga Penyuluhan dan Bantuan Hukum Nahdlatul Ulama (PBHNU) yang pada periode 2013/2017 diketuai oleh Haji Imam Makhali; dan Lembaga Bahtsul Masail (LBM) PCNU Kabupaten Blitar yang pada periode 2013/2017 diketuai oleh Kiai Ali Romzi.

Tak jauh dari hal di atas, NU cabang Kabupaten Blitar juga memiliki Lembaga Pendidikan Tinggi Nahdlatul Ulama (LPTNU) yang pada periode 2013/2017 diketuai oleh Prof. Dr. Zainuddin, M.Pd. Dari LPTNU inilah, pada tahu 2016 berdiri sebuah Universitas Nahdlatul Ulama (UNU) Blitar dengan 10 program studi sebagai berikut, antara lain: (1) Pendidikan Guru Sekolah Dasar; (2) Pendidikan Bahasa Indonesia; (3) Pendidikan Bahasa Inggris; (4) Pendidikan Olah Raga; (5) Teknik Mesin; (6) Teknik Sipil; (7) Teknik Ilmu Komputer; (8) Ilmu Matematika; (9) Ilmu Fisika; dan (10) Peternakan.

Begitu pula, NU cabang kabupaten Blitar hingga kini juga telah memiliki Lembaga Penanggulangan Bencana dan Perubahan Iklim Nahdlatul Ulama (LPBINU) yang pada periode 2013/2017 diketuai oleh Haji Imam Kusnin Ahmad. Sementara itu, NU cabang kabupaten Blitar juga memiliki beberapa hal berikut, antara lain: Muslimat NU yang periode 2015-2020 diketuai oleh Hj. Masluchi Saifulloh; PC. Fatayat NU diketuai oleh Hj. Imroh Nafifah; PC. IPNU Kabupaten Blitar periode 2017-2019 diketuai oleh Rijal Camelta Ghozwan; PC. IPPNU Kabupaten Blitar periode 2017-2019 diketuai oleh Zulia Khoirun Nisa'; Jam'iyatul Qurra' Wal Huffadh Nahdlatul Ulama (JQHNU) diketuai oleh Kiai Miftahul Khoir.

Di samping hal di atas, dalam pertanggungjawaban dalam konfercab XVII NU Kabupaten Blitar yang diadakan di Pondok Pesantren Mahyajatul Qurro' Kunir, Wonodadi, Blitar tanggal 22-24 Desember 2017, Lembaga Takmir Masjid Nahdlatul Ulama (LTM-NU) Kabupaten Blitar yang diketuai Kiai 
Muchammad Djaiz melaporkan rekap data masjid dan mushalla yang merupakan aset milik Nahdlatul Ulama (NU) cabang Blitar dengan uraian berikut: jumlah masjid 985 buah, jumlah mushalla 3850 buah, hingga total keseluruhan masjid dan mushalla yang benjadi aset milik NU cabang Kabupaten Blitar berjumlah 4835 buah.

Selanjutnya, NU cabang kabupaten Blitar juga telah memiliki Lembaga Falakiyah Nahdlatul Ulama (LFNU) yang pada periode 2012-2017 diketuai oleh Kiai Syamsul Hadi. Begitu pula, dalam laporan pertanggungjawabannya di konfercab XVII PCNU Kabupaten Blitar yang dilaksanakan di Pondok Pesantren Mahyajatul Qurro' Kunir, Lembaga Wakaf dan Pertanahan Nahdlatul Ulama (LWPNU) 2013/2017 yang diketuai oleh Kiai Muchtarom telah melaporkan berbagai tanah wakaf yang menjadi aset Nahdlatul Ulama di seluruh wilayah kabupaten Blitar yang telah digunakan sebagai pembangunan masjid, mushalla, madrasah diniyah (MADIN), Taman Kanak-kanak (TK), Taman Pendidikan alQur'an, dan lain sebagainya.

Hingga kini, NU cabang kabupaten Blitar juga telah memiliki Lembaga Amil Zakat Infak dan Sedekah Nahdlatul Ulama (LAZIZNU) sebagai ketua periode 2012-2017 adalah A. Muiszaki. LAZIZNU kabupaten Blitar yang memiliki visi "bertekad menjadi lembaga pengelola zakat, infak, dan sedekah yang didayagunakan secara amanah dan profesional untuk pendirian umat" dan telah mengkonsep tiga program (yakni, penguatan lembaga, pemungutan dana, dan distribusi) tersebut hingga kini memprioritaskan pada para yang berhak menerima program (mustahiq) berikut, antara lain: fakir miskin, anak yatim piatu, para penggiat dakwah/pejuang Islam, korban bencana alam, amil zakat, orang yang bepergian (ibnu sabil), dan orang yang Islamnya masih lemah (muallaf).

Demikianlah sekelumit tentang NU cabang kabupaten Blitar yang hingga kini masih menjadi ormas keagamaan yang secara mayoritas telah diikuti oleh masyarakat di wilayah kabupaten Blitar. Sebab diikuti oleh mayoritas masyarakat muslim di kabupaten Blitar, maka ormas NU cabang kabupaten Blitar memiliki potensi yang luar biasa bagi perkembangan kabupaten Blitar ke depan. Oleh karena itu, dalam konfercab XVII NU kabupaten Blitar, Riyanto Bupati Blitar (2017) menyatakan bahwa banyak sekali kerjasama dan kemitraan yang dibangun antara Pemerintah Kabupaten Blitar dengan Nahdlatul Ulama (NU) dalam berbagai bidang, baik kerjasama dengan dinas sosial, kesehatan, pendidikan, lingkungan hidup dan lain sebagainya. Dalam pidato tersebut Riyanto berharap agar kerjasama itu terus berjalan baik demi kemajuan kabupaten Blitar ke depan.

\section{Konstruk Rekomendasi Kebijakan Konfercab XVII NU Kabupaten Blitar}

Adapun konstruksi sosial para ulama dan pengurus NU cabang kabupaten Blitar berupa beberapa tausiyah atau rekomendasi Konfercab NU Kabupaten Blitar Masa Khidmat 2017-2022 yang diselenggarakan di Pondok Pesantren Mahyajatul Qurro' Kunir, Wonodadi, Blitar dalam studi ini terbagi menjadi tiga macam, antara lain: (1) tausiyah atau rekomendasi untuk pertimbangan arah kebijakan yang ditujukan kepada Pemerintah Kabupaten Blitar; (2) tausiyah atau rekomendasi untuk pertimbangan arah kebijakan yang ditujukan kepada pengurus cabang NU kabupaten Blitar; dan (3) tausiyah atau rekomendasi sebagai arah kebijakan yang ditujukan kepada seluruh warga NU di kabupaten Blitar. 
Pengertian kebijakan (policy) sendiri oleh Hornby (1995) diartikan sebagai sebuah rencana kegiatan atau pernyataan mengenai tujuan-tujuan yang diajukan atau diadopsi oleh suatu pemerintahan, partai politik dan lainnya. Kebijakan juga diartikan sebagai pernyataan-pernyataan mengenai kontrak penjaminan atau pernyataan tertulis. Dengan demikian, kebijakan pada konfercab XVII NU Kabupaten Blitar masa khidmat 2017-2022 dalam tulisan ini bisa diartikan sebagai sebuah rencana kegiatan atau pernyataan tertulis mengenai tujuan-tujuan yang dikonstruk oleh para ulama dan pengurus NU cabang kabupaten Blitar, setidaknya untuk masa khidmat 2017-2022 ke depan.

Dalam buku berjudul Rancangan Materi Konferensi Cabang XVII Nahdlatul Ulama Kabupaten Blitar disebutkan beberapa tausiyah atau rekomendasi yang ditujukan kepada Pemerintah Kabupaten Blitar sebagai pertimbangan pengambilan kebijakan program-program pemerintah, Dewan Perwakilan Rakyat Daerah (DPRD) Kabupaten Blitar, lembaga-lembaga yudikatif dan lain sebagainya yang tercantum dalam berbagai bidang berikut, antara lain:

\section{Bidang Pendidikan}

Hasil rancangan konfercab NU XVII kabupaten Blitar masa khidmat 2017-2022 memberikan tausiyah atau rekomendasi kepada pemerintahan Blitar sebagai arah pertimbangan mengambil kebijakan pada program bidang pendidikan yang isinya adalah:

Pertama, agar pemerintah kabupaten Blitar melanjutkan dan mengoptimalkan gerakan pemberantasan buta aksara al-Qur'an dan gerakan wajib madrasah diniyah bagi anak usia sekolah ke seluruh pelosok desa di kabupaten Blitar. Kedua, mendorong peningkatan alokasi anggaran pendidikan dan pendidikan keagamaan dari APBD, baik untuk pemeliharaan sarana dan prasarana maupun peningkatan alokasi anggaran untuk kesejahteraan tenaga pendidikan keagamaan (guru ngaji) di kabupaten Blitar. Ketiga, tidak membedakan alokasi anggaran pendidikan di bawah naungan Kementerian Pendidikan maupun Kementerian Agama di wilayah kabupaten Blitar. Keempat, memberikan tambahan perhatian dan pembinaan kepada lembaga-lembaga pendidikan di bawah naungan LP Ma'arif, Muslimat NU, dan Fatayat NU terkait peningkatan mutu dan kualitas sumber daya manusianya. Kelima, memberikan perhatian dan pembinaan kepada kader-kader pelajar dan santri NU untuk peningkatan sumber daya manusia dan wahana eksplorasi pelajar NU kabupaten Blitar.

Keenam, PCNU kabupaten Blitar meminta kepada Pemda/Bupati untuk menjamin bahwa sekolah-sekolah di kabupaten Blitar terutama SD/MI/sederajat dan SMP/MTs/sederajat akan tetap menjalankan enam hari masuk sekolah. Ketujuh, PCNU kabupaten Blitar meminta Bupati untuk membuat peraturan daerah (PERDA) yang menjamin keberlangsungan Taman Pendidikan al-Qur'an (TPQ) dan Madrasah Diniyah (MADIN) sebagai lembaga nonformal untuk memaksimalkan kegiatan pembelajarannya dalam rangka meningkatkan pendidikan karakter. Kedelapan, PCNU meminta kepada Bupati untuk menyeleksi guru-guru khususnya guru agama yang berfaham radikal di wilayah pemerintah daerah (PEMDA) agar mendapatkan pembinaan. 


\section{Bidang Ekonomi}

Sementara itu pula, konfercab XVJJ kabupaten Blitar memberikan beberapa rekomendasi kepada pemerintah Kabupaten Blitar dalam bidang ekonomi sebagai berikut, antara lain:

Pertama, agar pemerintah kabupaten Blitar memerluas akses permidalan, pembinaan, dan informasi kepada kelompok usaha mikro, usaha kecil dan menengah, koperasi pondok pesantren (kopontren) dan KSM warga Nahdlatul Ulama. Kedua, agar pemerintah kabupaten Blitar memfasilitasi dan mendorong optimalisasi kerja Himpunan Pengusaha Nahdliyin (HPN) cabang kabupaten Blitar sebagai media interaksi, komunikasi, dan pembelajaran bagi calon-calon pengusaha nahdliyin. Ketiga, himbauan keaktifan warga Nahdliyin (NU) dengan berperan aktif dalam mengawal dan mengoptimalkan penggunaan Alokasi Dana Desa (ADD) supaya sesuai dengan peruntukan kemaslahatan umat dan tidak meninggalkan alokasi untuk kegiatan keagamaan.

\section{Bidang Sosial}

Tak jauh dari kedua hal di atas, konfercab XVII NU kabupaten Blitar juga memberikan tausiyah atau rekomendasi kepada pemerintah kabupaten Blitar dalam bidang sosial sebagai berikut, antara lain:

Pertama, tetap konsisten terhadap substansi peraturan daerah nomer 15 tahun 2008 tentang Pelarangan dan Penanganan Prostitusi di seluruh kabupaten Blitar yang terindikasi hendak muncul kembali melalui sarana hiburan karaoke keluarga, pub, hotel, penginapan, sarana hiburan malam, dan sarana sejenis pasca ditutupnya Lokalisasi resmi Wanita Tuna Sosial (WTS). Kedua, melalui perangkat pemerintahan yang ada (Satpol PP, Kepolisian, Kejaksaan, Badan Narkotika Nasional (BNN) untuk senantiasa menggiatkan pemberantasan penyakit masyarakat, kriminalitas, perjudian, peredaran togel, pornografi, minuman keras dan narkoba. Ketiga, mencegah adanya organisasi yang berfaham radikal dan yang mempunyai indikasi menjauhkan warga Nahdliyin (NU) kabupaten Blitar dari kecintaan Negara Kesatuan Republik Indonesia (NKRI). Keempat, PCNU kabupaten Blitar meminta kepada Bupati untuk mengoptimalkan pelaksanaan peraturan daerah (PERDA) keagamaan seperti peraturan daerah Badan Amil Zakat, peraturan daerah tentang haji, peraturan daerah tentang minuman keras atau beralkohol dan obat psikotropika. Kelima, mendorong Kementerian Agama (Kemenag) kabupaten Blitar untuk meningkatkan pelayanan masyarakat.

\section{Bidang Kesehatan}

Adapun tausiah atau rekomendasi konfercab NU XVII kabupaten Blitar dalam bidang kesehatan yang ditujukan kepada Pemerintah Kabupaten Blitar dapat dijelaskan sebagai berikut, antara lain:

Pertama, menyediakan pelayanan kesehatan yang memadai dan terjangkau bagi masyarakat dengan memperluas alokasi anggaran untuk masyarakat miskin di wilayah kabupaten Blitar supaya masuk menjadi peserta BPJS. Kedua, mengajak kerjasama dengan Lembaga Kesehatan Nahdlatul Ulama (LKNU) dalam upaya meningkatkan pelayanan kesehatan kepada warga Nahdliyin (NU) di pelosok wilayah kabupaten Blitar. 


\section{Bidang Partisipasi Masyarakat}

Sementara itu, lain daripada hal yang telah disebutkan di atas bahwa konfercab NU XVII kabupaten Blitar juga memberikan tausiyah atau rekomendasi terkait kebijakan di bidang partisipasi masyarakat kepada Pemerintah Kabupaten Blitar sebagai berikut, antara lain:

Pertama, mengoptimalkan peran serta organisasi atau lembaga-lembaga kemasyarakatan yang benar-benar memiliki basis riil di dalam masyarakat. Kedua, menjalankan pembangunan yang berkeadilan dan senantiasa mengutamakan kepentingan masyarakat yang lebih banyak bukan kepentingan pribadi atau golongan. Ketiga, mendorong Kementerian Agama (Kemenag) untuk mensinergikan tempat-tempat wisata di Kabupaten Blitar menjadikan wisata syariah (adanya mushalla yang suci dan bersih).

Semua hal di atas merupakan tausiyah atau rekomendasi konfercab NU XVII kabupaten Blitar yang dikonstruk oleh para ulama dan pengurus NU cabang kabupaten Blitar dan ditujukan kepada Pemerintah Kabupaten Blitar agar dapat menjadi pertimbangan pengambilan kebijakan dan program-program pemerintah, sehingga semua itu bisa disinergikan dengan tujuan-tujuan NU cabang kabupaten Blitar mendatang. Atau setidaknya bisa disinergikan dengan tujuan-tujuan yang hendak dicapai oleh NU cabang kabupaten Blitar masa khidmat 2017-2022 ke depan. Sementara itu, ada beberapa tausiyah atau rekomendasi kebijakan yang dikonstruk para ulama dan pengurus NU cabang kabupaten Blitar dalam konfercab XVII NU kabupaten Blitar yang juga ditujukan kepada pengurus cabang NU kabupaten Blitar sebagai berikut, antara lain:

Pertama, untuk segera melaksanakan anmanat konfercab, menyusun kepengurusan (pengurus harian, lembaga, maupun lajnah) sesuai dengan AD/ART organisasi, dan sesuai dengan Peraturan Pokok Organisasi dan Administrasi (PPOA) NU yang terbaru, serta Pedoman Tata Kerja Pengurus Cabang. Kedua, dalam merekrut pengurus harian, lembaga/lajnah hendaknya memperhatikan kinerja selama ini, profesionalitas sesuai bidangnya, dan kesediaan masingmasing personil untuk diganti antarwaktu jika mampu aktif lagi dalam masa kepengurusan. Ketiga, mampu mencegah intervensi kepentingan polotik praktis yang hendak membawa NU secara institusi untuk kepentingan partai tertentu, kepentingan perorangan dalam pilihan legislatig (pileg), pilihan presiden (pilpres), pilihan gubernur (pilgub) maupun pilihan bupati (pilbub) yang beresiko memecah belah ulama dan warga Nahdliyin (NU). Keempat, mempertahankan secara institusi NU tetap netral dalam semua kepentingan politik aliran, memilih untuk menjadi pelindung dan pengayom bagi semua golongan sesuai Khittah NU tahun 1926 berdasarkan Qonun Asasi KH. Muhammad Hasyim Asyari dalam upaya menjaga dan melestarikan amalan-amalan Nahdlatul Ulama (amaliyah nahdliyah) berasarkan paham Ahlusunnah Wal Jamaah (Aswaja). Kelima, menjadi patner kritis pemerintah dalam pengertian mendukung kebijakan pemerintah yang baik, maslahat dan bernilai ibadah, namun berani mengingatkan kebijakan pemerintah yang mungkar, maksiat, korupsi, kolusi, dan nepotisme.

Adapun beberapa tausiyah atau rekomendasi konfercab XVII NU kabupaten Blitar yang ditujukan kepada seluruh warga Nahdlatul Ulama di wilayah kabupaten Blitar terbagi menjadi tiga hal, antara lain: 
Pertama, lebih mengaktifkan kembali majelis-majelis taklim yang ada di semua tingkatan, baik yang sudah rutin diselenggarakan seperti tahlilan, diba'an, khataman al-Qur'an, manakiban, dala'ilan, Lailatul Ijtima', pengajian Selapan, madrasah diniyah (MADIN), Taman Pendidikan al-Qur'an (TPQ), dan semacamnya ataupun kegiatan yang bersifat insidental seperti peringatan hari-hari besar Islam (PHBI), pida'an orang meninggal, halaqoh keagamaan, dan lain sebagainya. Kedua, mendorong semua warga Nahdliyin (NU) untuk berperan aktif dalam pembangunan di semua tingkatan seperti bersedia menjadi pengurus RT, $\mathrm{RW}$, perangkat dusun, tokoh agama (modin), perangkat desa, BPD, LPPD, komite sekolah, organisasi kecamatan ataupun organisasi kabupaten, MUI, FKUB, FKDM, BNN, Dewan Pendidikan, dan semacamnya sebagai upaya membangun kemaslahatan umat dari dalam. Ketiga, senantiasa berkoordinasi, menjaga budaya silaturahim, menimbang (tabayun), saling berkomunikasi dengan tokoh-tokoh dan pengurus NU yang terdekat untuk menghindari saling curiga, permusuhan, fitnah dan kesalahpahaman karena informasi yang didapatkannya tidak utuh.

Demikianlah pembahasan beberapa tausiyah atau rekomendasi pada konfercab XVII NU kabupaten Blitar yang telah dikonstruk oleh para ulama dan pengurus cabang NU kabupaten Blitar dan ditujukan kepada beberapa pihak, antara lain: (1) kepada Pemerintahan Kabupaten Blitar; (2) kepada pengurus NU cabang kabupaten Blitar terbaru; dan (3) kepada seluruh warga Nahdlatul Ulama yang berada di wilayah kabupaten Blitar. Dari konstruk para ulama dan pengurus NU cabang kabupaten Blitar itulah yang akan menentukan perjalanan NU cabang Blitar di masa mendatang.

\section{KESIMPULAN}

Dari uraian di atas dapat disimpulkan bahwa bahwa para ulama dan pengurus NU cabang kabupaten Blitar telah mengkonstruk beberapa rekomendasi kebijakan yang ditujukan kepada Pemerintah Kabupaten Blitar meliputi lima hal, yaitu bidang pendidikan, ekonomi, sosial, kesehatan, dan partisipasi masyarakat. Selain itu, konfercab ini juga mengkonstruk beberapa tausiyah atau rekomendasi kebijakan yang ditujukan kepada pengurus cabang NU kabupaten Blitar terbaru dan warga NU secara keseluruhan dalam rangka membangun sinergi menuju NU ke depan yang lebih mandiri.

Tentu saja, rekomendasi kebijakan yang dikeluarkan konfercab XVII NU kabupaten Blitar tersebut apabila dianalisis dengan teori konstruksi sosial Berger dan Luckmann merupakan bagian dari eksternalisasi para ulama dan pengurus NU cabang kabupaten Blitar yang di masa mendatang diharapkan akan melembaga atau menjadi pola serta terinternalisasi dalam diri pemangku kebijakan Pemerintahan Kabupaten Blitar, pengurus NU cabang kabupaten Blitar, dan warga Nahdliyin (NU) se-kabupaten Blitar hingga akhirnya benar-benar menjadi sebuah pola pikir, sikap, dan tindakan yang real dan selaras dengan tema konfercab tersebut, yakni membangun sinergi demi terwujudnya NU mandiri.

\section{SARAN}

Dari kesimpulan di atas ada sebuah saran bahwa apa yang dikonstruk para ulama dan pengurus NU cabang kabupaten Blitar menjadi suatu hal yang layak diperhatikan dan dilaksanakan oleh berbagai pihak yang bersinergi di dalamnya, antara lain: Pemerintah Kabupaten Blitar, pengurus NU cabang 
Kabupaten Blitar terbaru, dan seluruh warga Nahdliyin (NU) di wilayah kabupaten Blitar. Hal tersebut perlu dilakukan karena ada keterkaitan berbagai tujuan yang dikonstruk para ulama dan pengurus NU cabang kabupaten Blitar masa kini dengan masa depan. Sebab tujuan-tujuan yang dikonstruk masa kini akan menentukan hasilnya di masa mendatang.

\section{DAFTAR RUJUKAN}

Abdusshomad, Muhyiddin, 2010. Hujjah NU Akidah - Amaliah - Tradisi. Surabaya: Penerbit Khalista dan Lajnah Ta'lif Wan Nasr (LTN NU) Jawa Timur.

Anam, Choirul, 2010. Pertumbuhan dan Perkembangan NU. Sala: Penerbit PT. Duta Aksara Mulia.

Berger, P. L. dan Thomas Luckman, 2013. Tafsir Sosial atas Kenyataan: Risalah tentang Sosiologi Pengetahuan, terj. Hasan Basari. Jakarta: LP3S.

Bogdan, Robert C. \& Sari Knopp Biklen, 1998. Qualitative Research for Education: An Introduction to Theory and Methods. London: Allyn and Bacon, 1998.

Fadeli, Soelaiman dan Muhammad Subhan, 2012. Antologi NU Sejarah - Istilah Amaliah - Uswah Buku I. Surabaya: Penerbit Khalista dan Lajnah Ta'lif Wan Nasr (LTN NU) Jawa Timur. , 2014. Antologi NU Sejarah - Istilah - Amaliah - Uswah Buku II. Surabaya: Penerbit Khalista dan Lajnah Ta'lif Wan Nasr (LTN NU) Jawa Timur.

Hakam, Saiful, 2017. Menjadi Modern dan Religius: Perguruan NU di Blitar 1950an-1970an. Briliant Jurnal Riset Dan Konseptual, 2(4):544-553. DOI: http://dx.doi.org/10.28926/briliant.v2i4.119.

Hornby, AS, 1995. Oxford Advanced Leaner's Dictionary of Current English. Oxford: Oxford University Press.

Imron, Fuad Amin, 2016. Syaikhona Kholil Bangkalan Penentu Berdirinya Nahdlatul Ulama. Surabaya: Penerbit Khalista.

Ngangi, Charles. R., 2011. Konstruksi Sosial dalam Realitas Sosial. ASE, 7(2):1, http://ejournal.unsrat.ac.id.

Riyanto, 2017. Pokok-pokok Sambutan Bupati Blitar pada Acara Pembukaan Konferensi Cabang Ke XVII Nahdlatul Ulama Kabupaten Blitar. Pidato disampaikan dalam acara Konfercab XVII NU Kabupaten Blitar di Pondok Pesantren Mahyajatul Qurro' Kunir Wonodadi, Jumat 22 Desember 2017.

Siradj, Said Aqil, 2016. "Menyingkap Jejak Syaikhona Kholil Bangkalan dalam Proses Pendirian NU" dalam Fuad Amin Imron, 2016. Syaikhona Kholil Bangkalan Penentu Berdirinya Nahdlatul Ulama. Surabaya: Penerbit Khalista.

Stake, Robert E., "Case Studies", dalam Norman K. Denzin \& Yvonna S. Lincoln (ed.), 1994. Handbook of Qualitative Research. London: Sage Publications.

Tim Aswaja NU Center PWNU Jawa Timur, 2016. Risalah Ahlussunnah WalJama'ah Dari Pembiasaan Menuju Pemahaman dan Pembelaan AkidahAmaliah NU. Surabaya: Penerbit Khalista. 
Tim Penyusun, 2017. Rancangan Materi Konferensi Cabang XVII Nahdlatul Ulama Kabupaten Blitar. Makalah disampaikan pada Konfercab NU XVII Kabupaten Blitar di Pondok Pesantren Mahyajatul Qurro' Kunir, 22-24 Desember 2017.

, 2017. Laporan Pertanggungjawaban PCNU Kabupaten Blitar Masa Khidmad 2013-2017. Makalah disampaikan pada Konfercab NU XVII Kabupaten Blitar di Pondok Pesantren Mahyajatul Qurro' Kunir, 22-24 Desember 2017.

Tim Revisi POA PWNU Jawa Timur, 2015. Pedoman Organisasi dan Administrasi PWNU Jawa Timur. Surabaya: LTN Pustaka - PW LTNNU Jawa Timur. 